\title{
DOCTRINA
}

\section{Carabineros y autonomía policial en Chile: Una aproximación legal-institucional}

\author{
Carabineros and police autonomy in Chile: A legal-institutional approach
}

\author{
Pablo Contreras Vásquez (iD \\ Universidad Autónoma de Chile \\ Ricardo Montero Allende (iD) \\ Abogado, Chile \\ Sebastián Salazar Pizarro (iD \\ Universidad de O'Higgins, Chile
}

\begin{abstract}
RESUMEN El texto analiza los principales factores, tanto legales como institucionales, que han potenciado la autonomía de Carabineros. Se examina el origen del marco normativo que regula la institución armada, considerando su evolución histórica desde el período de la dictadura cívico-militar chilena, y atendiendo a la regulación constitucional, orgánico constitucional, legal y reglamentaria. Si bien las reformas constitucionales de 2005 modificaron gran parte de la autonomía política-institucional de Carabineros, el trabajo concluye que la regulación infraconstitucional preserva importantes espacios de autonomía operativa-funcional de esta rama de la policía chilena.
\end{abstract}

PALABRAS CLAVE Carabineros, policía, autonomía policial, legislación policial, regulación constitucional.

ABSTRACT The text analyses the main factors, both legal and institutional, that have enhanced the autonomy of Carabineros. The origin of the normative framework that regulates the armed institution will be examined, considering its historical evolution since the period of the Chilean civic-military dictatorship, and taking into account the constitutional, organic constitutional laws, legal and administrative regulations. Although the constitutional reforms of 2005 modified a large part of the political-institutional autonomy of the Carabineros, the paper concludes that the infra-constitutional regulation preserves important spheres of operational-functional autonomy of this branch of the Chilean police.

KEYWORDS Carabineros, police, police autonomy, police regulations, constitutional regulation. 


\section{Introducción}

Carabineros es una institución que presenta una paradoja. Dentro del orden constitucional, es un organismo de máxima importancia, ya que existe «para dar eficacia al derecho, garantizar el orden público y la seguridad pública interior» (Constitución Política de la República de Chile, 1980: artículo 101, inciso segundo). ${ }^{1}$ En cuanto al número de efectivos, es la principal rama de las policías, esto es, de las Fuerzas de Orden y Seguridad Pública. Se trata del brazo armado del Estado para desplegar - en términos weberianos- el monopolio de la violencia legítima al interior de su territorio. Su función, por tanto, es crítica para el cumplimiento de la legalidad vigente. Su peso, además, es significativo dentro de la Administración del Estado. Es el servicio público con mayor presencia en el territorio de la República. De acuerdo con las últimas cifras publicadas por Carabineros, a fines de 2019 la institución contaba con 59.674 funcionarios y, de aquellos, el 80,7\% correspondía al escalafón de orden y seguridad (Carabineros de Chile, 2020: 9). Tanto su función como su envergadura debiese reclamar la atención de un estudio profundo sobre la institución.

Sin embargo, no ha sido así. Al menos en la literatura jurídica nacional, no es posible encontrar trabajos monográficos sobre la institución, sus funciones, atribuciones y estructura, entre otras materias. ${ }^{2}$ En el derecho público, en general, no existe un estudio crítico sobre la institución, más allá de su descripción basal por las reglas constitucionales que se refieren a Carabineros (Verdugo Marinkovic, Pfeffer Urquiaga y Nogueira Alcalá, 2002: 331-334; Molina Guaita, 2006: 520-521; Nogueira Alcalá, 2012). En el ámbito penal y procesal penal, la situación no difiere sustantivamente. Pese al rol que cumple en la prevención y la persecución criminal, el estudio de Carabineros es fragmentario y se relaciona con las reglas específicas de operación bajo el Código Procesal Penal, por ejemplo, en sus actuaciones sin orden judicial previa, entre otras materias.

Y ahí radica la paradoja. ¿Cómo es posible que una institución que formó parte de la Junta de Gobierno que lideró la dictadura cívico-militar, que adoptó buena parte de las leyes que hoy nos rigen en distintas materias, carezca de un estudio acucioso desde la vereda del derecho? ¿Por qué Carabineros no ha sido examinado en su estructuración, funciones y atribuciones de cara a un Estado democrático de derecho?

No es nuestro objetivo explicar la paradoja. Por el contrario, este texto tiene por

1. La Constitución, en el artículo citado, nomina a la institución que es objeto de estudio de este trabajo como «Carabineros». Sin embargo, la Ley Orgánica Constitucional de Carabineros de Chile, 18.961, del 7 de marzo de 1990, prefiere la forma «Carabineros de Chile». No hay duda de que el legislador orgánico constitucional carece de competencias para cambiarle el nombre a una institución recogida en la Constitución. En adelante, se utilizará el nombre de «Carabineros» fijado por esta última, salvo que conste como tal en una norma jurídica o en el nombre oficial de otra institución.

2. La sociología y la ciencia política nacional sí han abordado a las policías, en términos generales, y a Carabineros, en particular. Varios de estos trabajos son citados a lo largo de este texto en lo que es pertinente. En materia jurídica, sin embargo, no ha sido posible encontrar un símil de masa crítica sobre el objeto de estudio. 
objeto contribuir a develar algunas de las características institucionales de Carabineros y su operación y funcionamiento a partir de una revisión de su marco normativo, considerando el período que va desde el quiebre constitucional y la posterior dictadura cívico-militar hasta la actualidad. En otras palabras, el objetivo es determinar cuáles son las reglas, competencias y procedimientos que prefiguran y condicionan el actuar de Carabineros. Con ello, se pretende saldar — al menos en parte- la deuda de la literatura con respecto al estudio crítico-jurídico de la policía en nuestro país.

En este contexto, este trabajo busca analizar los principales factores que han potenciado la autonomía de Carabineros. Se examinará el origen del marco normativo que regula la institución policial, considerando su evolución histórica desde el período de la dictadura cívico-militar chilena, atendiendo a la relevancia de la regulación constitucional, orgánico constitucional, legal y reglamentaria desarrollada, en virtud de la función institucional asignada a la citada fuerza en dicho período. Además, se considerarán factores transversales como el rol de la conducción política, la autonomía de Carabineros y su equiparación normativa con las ramas militares.

Dentro de esta revisión, se explorarán las atribuciones que fueron entregadas a la policía uniformada durante la dictadura - especialmente a través de leyes de "amarre»- y como estas fueron protegidas por resguardos mayoritarios contenidos en la Constitución de 1980. Para ello, se describirán los principales hitos que marcaron las relaciones cívico-policiales durante el período escogido.

Con respecto a los órganos del Estado, el artículo 7, inciso primero, de la Constitución, reconoce expresamente que «actúan válidamente previa investidura regular de sus integrantes, dentro de su competencia y en la forma que prescriba la ley». En tal sentido, todo órgano estatal -incluido, lógicamente, Carabineros - necesita en su actuación ciertos niveles de autonomía para, dentro de sus competencias, poder cumplir los objetivos que la ley le encomienda. Sin perjuicio de lo anterior, dicha autonomía debe interpretarse en concordancia con las atribuciones de otros órganos del Estado, particularmente de aquellos de los cuales existe dependencia, y respetando las limitaciones que otros preceptos constitucionales y legales establecen.

El momento histórico que está atravesando la institución es particularmente propicio para la reflexión sobre su funcionamiento. De una parte, su actuar autónomo ha generado incentivos para actos de corrupción sistémica al interior de Carabineros. El denominado Pacogate provocó el descabezamiento del alto mando institucional, generando una investigación penal de una serie de irregularidades (Weibel, 2018). De otra parte, la forma en que Carabineros controla el orden público ha sido sometida a un intenso escrutinio público durante los últimos años. Particularmente notorias, en el contexto de las masivas manifestaciones provocadas por la crisis social que detonó en octubre de 2019, han sido las denuncias de violaciones graves a los derechos humanos en el marco de la represión policial a las marchas y protestas (Instituto Nacional de Derechos Humanos, 2019; Oficina del Alto Comisionado para los Derechos Humanos de Naciones Unidas, 2019). Este actuar autónomo tiene condiciones normativas que per- 
miten que la institución se comporte sin el debido control ni la efectiva subordinación al poder civil democráticamente electo.

Parece existir un consenso generalizado en la necesidad de transformar la institución de Carabineros para direccionar y controlar su actuar. A mediados de 2018, a instancias del gobierno, fue presentado un informe elaborado por diversos actores en el contexto del llamado «Acuerdo Nacional por la Seguridad Pública». Tomando como base algunas recomendaciones, el presidente Sebastián Piñera presentó una serie de proyectos de ley que tenían como objetivo la modernización de las policías. ${ }^{3}$ Luego, y como consecuencia de la crisis social por la que atravesaba el país, el primer trimestre de 2020 fueron presentados dos nuevos informes, con propuestas para reformar Carabineros, más allá de una simple modernización. El primero fue elaborado por la Comisión de Reforma a Carabineros, compuesta por un grupo transversal de académicos, políticos y expertos en materia de seguridad, al alero de la Comisión de Seguridad del Senado. ${ }^{4} \mathrm{El}$ segundo informe fue preparado por el Consejo para la Reforma de Carabineros, compuesto por autoridades y expertos, convocado por el Ministerio de Interior y Seguridad Pública. ${ }^{5}$ Ambos informes coincidieron en que era urgente una reforma estructural de Carabineros.

El trabajo se organiza de la siguiente forma. Primero, se revisa el rol de la conducción política de Carabineros bajo un Estado democrático de derecho y cuál ha sido la situación en Chile. En segundo lugar, se analiza la dimensión constitucional de la autonomía institucional y operativa de Carabineros, considerando la pronta equiparación militar entre Carabineros y las Fuerzas Armadas durante la dictadura y la consagración de normas constitucionales que sellaron su rol dentro del «Poder de Seguridad» de la democracia protegida de la dictadura. Si bien las reformas constitucionales de 2005 desmantelaron el «poder de seguridad», no se alcanzó a tocar la estructura jurídica de funcionamiento autónomo a nivel infraconstitucional.

Por ello, la última sección examina dos niveles de autonomía: la político-institucional, referida al rol que cumple (y cumplió) la institución policial en nuestro sistema político y jurídico; y la operativa funcional. El texto concluye que la estructura jurídi$\mathrm{ca}$, generada en la dictadura, consolida un marco institucional y operacional para el funcionamiento autónomo de Carabineros, que incide en un débil control civil y con amplios espacios discrecionales reservados a este órgano.

\section{La conducción política de Carabineros y el régimen democrático}

En un Estado democrático, los responsables de cautelar el ejercicio de la fuerza estatal son las autoridades civiles electas democráticamente. El principio de legitimidad de-

3. «Proyectos de Ley. Acuerdo Nacional por la Seguridad Pública», Gobierno de Chile, 2020, disponible en bitly.is/3kERVly.

4. «Somos», Comisión de Seguridad, disponible en bit.ly/36OrsJX.

5. «Consejo de Reforma a Carabineros», Gobierno de Chile, 2020, disponible en bit.ly/3eDzc1U. 
mocrática, y su fundamento en las cláusulas constitucionales de república democrática y de soberanía, establecen las bases normativas de este poder y responsabilidad. Sin embargo, las reglas sustantivas y orgánicas que estructuren este deber de control pueden ser de distinta magnitud. En este apartado, se analiza cómo el concepto de seguridad nacional, establecido en la Constitución, fundamentó una arquitectura de poder militar y policial al margen del control democrático de las autoridades civiles.

En Chile, el concepto fundante contenido en la Constitución de 1980 es el término «seguridad nacional». Este se asocia al período de la guerra fría y fue tanto promovido como ejecutado por los gobernantes de diversos países latinoamericanos con la intención de combatir cualquier ideología contraria a sus intereses, particularmente aquellas asociadas a posturas de la izquierda política (Flisfisch y Robledo, 2012; Pion-Berlin y Martínez, 2017). El término en cuestión sirvió de paraguas ideológico que amparó la transición democrática en materia de seguridad y que ha determinado las relaciones civiles-militares y civiles-policiales luego de terminada la dictadura.

$\mathrm{Ni}$ el concepto enunciado a nivel constitucional ni su soporte normativo han sido objeto de una adecuada reformulación democrática durante las últimas décadas. Si bien se ha logrado mantener una separación de roles entre las Fuerzas Armadas y las policías, no se ha logrado atenuar la militarización de Carabineros ni sus niveles de actuación autónoma. Es más, en la práctica, con posterioridad a la dictadura, la equiparación normativa entre las Fuerzas Armadas y Carabineros terminó consolidándose $\mathrm{y}$, en materias puntuales - como con respecto a la discrecionalidad en el manejo de los recursos públicos-, exacerbándose. Lo mismo que sucedió con respecto a la conducción política, las falencias en la dirección y el control civil de las Fuerzas Armadas (Agüero y Fuentes, 2009: 16) terminó replicándose en Carabineros.

La transición a la democracia se desarrolló, en gran medida, condicionada a los términos impuestos por la Constitución (Atria, 2013; Atria, Salgado y Wilenmann, 2017; Heiss, 2020), particularmente en materias de seguridad y defensa (Agüero, 2003). Consistente con la prelación del liderazgo militar de la dictadura que le dio origen, toda la norma fundamental construye un diseño institucional que prioriza a las Fuerzas Armadas (que, a su vez, se ordenan por antigüedad, es decir, Ejército, Armada y Fuerza Aérea), luego a Carabineros (policía uniformada) y, finalmente, a la Policía de Investigaciones (policía civil). Esta preferencia se ha mantenido durante la democracia.

El principal hito en las relaciones cívico-militares y las relaciones entre el poder civil y Carabineros son, sin duda, las reformas constitucionales de 2005. Estas reformas lograron destrabar algunas de las principales limitaciones que el texto original de la Constitución había establecido para imposibilitar una efectiva dirección y control de las instituciones armadas. Sin perjuicio de aquellas modificaciones, poco tiempo después se hizo evidente que estas no eran suficientes (Agüero y Fuentes, 2009: 14) y, durante la última década, esto se hizo incuestionable.

La Constitución aún mantiene una serie de distorsiones en la regulación de las Fuerzas Armadas y Carabineros. Un símbolo expreso de la integración de las Fuerzas Armadas y Carabineros a la orgánica militar y su desencaje con la orgánica política es 
el Consejo de Seguridad Nacional. Otro caso, y solo explicable por razones históricas, es el capítulo que regula a las Fuerzas Armadas y a las policías o el capítulo que regula al Consejo de Seguridad Nacional, los que tienen un quórum reforzado de reforma constitucional establecido en el artículo 127, inciso segundo, de la Constitución. Esto marca una gran diferencia con el resto de la institucionalidad. Por ejemplo, en la actualidad, para realizar cualquier cambio constitucional con respecto a los tres poderes del Estado (capítulos IV, V y VI), es necesario un acuerdo de tres quintos de los diputados y senadores en ejercicio, mientras que para modificar las Fuerzas Armadas y las policías (capítulo XI) o el Consejo de Seguridad Nacional (capítulo XII), se requiere alcanzar las dos terceras partes de los parlamentarios en ejercicio. Dicho quórum excepcional solo lo comparten con las bases de la institucionalidad, los derechos y deberes constitucionales, el Tribunal Constitucional y con el capítulo de Reforma Constitucional y del Procedimiento para Elaborar una nueva Constitución de la República (capítulos I, III, VIII y XV respectivamente). Tras tres décadas de democracia, todavía las Fuerzas Armadas y las policías cuentan con un resguardo a nivel constitucional injustificado, que incluso excede al del poder civil democráticamente electo - Poder Ejecutivo y Congreso Nacional- y al Poder Judicial.

La positiva evaluación que por muchos años ha tenido Carabineros por parte de la población, condicionó y limitó reformas más estructurales en dicha institución (Dammert, 2016). Sin perjuicio de lo anterior, el poder político, por acción u omisión, delegó en la práctica gran parte de sus facultades de dirección y control sobre Carabineros, potenciando la autonomía de la institución. Esta injustificable falencia de conducción hizo evidente que, mientras más deficiente es la conducción política, mayor es el riesgo de una actuación autónoma exacerbada por parte de la policía uniformada y mayor la exposición a la ocurrencia de delitos, abusos y violaciones a los derechos humanos (Montero Allende, 2019).

En tal sentido, si bien las falencias en la dirección y el control civil de Carabineros -tanto desde el Ejecutivo como desde el Congreso Nacional - tienen su origen en diversos factores, uno de los principales es el marco normativo que rige a dicha institución. Carabineros ha sabido capitalizar las herramientas y facultades normativas extraordinarias que fueron construidas durante la dictadura, para consolidar un nivel de autonomía que lo sitúa como una excepción institucional con respecto a las normas generales que rigen a otros órganos de la administración pública. A continuación, revisaremos algunas de ellas.

\section{La dimensión constitucional del problema de la autonomía y equiparación militar de Carabineros}

\section{La equiparación militar de Carabineros en la Junta Militar de gobierno}

El proceso de militarización de la función policial tiene diversos antecedentes históricos que han sido destacados por la literatura, desde su fundación, pasando por la dictadura militar (Maldonado Prieto, 1990; Águila y Maldonado, 1996: 81; Vallejos Muñoz, 
2019: 3-4). En lo que a este texto interesa, buscaremos los antecedentes jurídicos que normativizaron la equiparación militar de Carabineros y su posterior integración en el esquema de control de la democracia protegida que estableció la Constitución de 1980. La militarización, aquí analizada, se diferencia de los motivos iniciales de la construcción de una policía disciplinada y jerárquicamente estructurada. A su vez, se distingue también de la reforma a la Constitución de 1925 que, en 1971, tras la reforma de la Ley 17.398, definió a la "fuerza pública», integrada por las Fuerzas Armadas y el cuerpo de Carabineros, sometiendo su acción al poder civil, democráticamente electo, al disponer que eran «instituciones esencialmente profesionales, jerarquizadas, disciplinadas, obedientes y no deliberantes» (Constitución Política de la República de Chile, 1925-1971: artículo 22). Como se revisa en este apartado, la militarización posterior a 1973 tiene por objeto asimilar el estatus político y funcional de Carabineros con las Fuerzas Armadas, dada su integración en el mando de la dictadura. Esto tendrá, como consecuencia, la estructuración de un nuevo marco legal-institucional en que comparte numerosas esferas de autonomía con las Fuerzas Armadas.

En 1973, Carabineros se plegó a las Fuerzas Armadas en el golpe de Estado contra el gobierno democrático del presidente Salvador Allende. Desde la primera normatividad del régimen dictatorial en ciernes, Carabineros recibe el mismo status que el resto de las Fuerzas Armadas. En efecto, como bien se lee en el Bando 1:

Las Fuerzas Armadas y Carabineros están unidos para iniciar la histórica y responsable misión de luchar por la liberación de la patria y evitar que nuestro país siga bajo el yugo marxista; y la restauración del orden y la institucionalidad (Junta Militar de Gobierno de Chile, 1973a: sección 2, énfasis agregado).

Asimismo, el Bando 5 prescribía que:

Las Fuerzas Armadas han asumido el deber moral que la patria les impone de destituir al gobierno que, aunque inicialmente legítimo, ha caído en la ilegitimidad flagrante, asumiendo el poder por el solo lapso en que las circunstancias lo exijan, apoyado en la evidencia del sentir de la gran mayoría nacional, lo cual, de por sí, ante Dios y ante la historia, hace justo su actuar $y$, por ende, las resoluciones, normas e instrucciones que se dicten para la consecución de la tarea de bien común y de alto interés patriótico que se dispone cumplir (Junta Militar de Gobierno de Chile, 1973b: sección 13).

Este último bando fue firmado conjuntamente por las Fuerzas Armadas y por Carabineros, a pesar de que el párrafo citado solo se refiere a las primeras. ¿Por qué firmar algo que no menciona expresamente a Carabineros en el deber de asumir el mando? Una posibilidad es la de una mera omisión. Pero, también, la omisión buscaba la equiparación de Carabineros con los institutos armados, es decir, Carabineros se «autocomprendía» institucionalmente bajo el rótulo de «Fuerzas Armadas».

En cualquier caso, los primeros decretos de leyes despejan cualquier duda sobre el punto. Siguiendo el concepto de fuerza pública existente bajo la Constitución de 1925, integrada por las Fuerzas Armadas y Carabineros (el ya citado artículo 22, modificado 
por la Ley 17.398 de 1971), el Decreto Ley 1 declara que estas instituciones representan «la organización que el Estado se ha dado para el resguardo y defensa de su integridad física y moral, y de su identidad histórico-cultural» y, en base a ello, «se constituyen en Junta de Gobierno y asumen el Mando Supremo de la Nación» (Decreto Ley 1, 1973: considerando 1 y artículo 1). Bajo esta estructura de gobierno, Carabineros pasará a formar parte de una serie de reglas que irán equiparando su estatus con el de las Fuerzas Armadas. El estatus militarizado de Carabineros se consolidará con la creación del «Poder de Seguridad» en la Constitución de 1980 y con la respectiva legislación orgánico constitucional que lo regulará conforme a ella. Hasta el día de hoy, la Ley Orgánica Constitucional de Carabineros de Chile 18.961 del 7 de marzo de 1990, en su artículo 1, define a Carabineros de Chile como «una institución policial técnica y de carácter militar».

La integración de Carabineros en el «Poder de Seguridad» de la Constitución de 1980

La Constitución de 1980 marcó un quiebre con la tradición constitucional chilena en materia de las reglas aplicables a las Fuerzas Armadas y a Carabineros. Como bien señaló un autor, «las Fuerzas Armadas logran un estatus desconocido para la doctrina constitucional democrática» (Godoy, 1996: 295; Peña, 2005; Verdugo Marinkovic, 2005; Contreras, 2015: 316-321), reservando un capítulo especial para ellas y regulando los aspectos básicos de su organización, funciones y designaciones de los mandos, así como en su particular rol en el inédito órgano llamado Consejo de Seguridad Nacional.

En la generación de la Constitución de 1980, la Comisión de Estudios para la Nueva Constitución recibió un documento de la misma Junta Militar con las instrucciones para configurar un «Poder de Seguridad» en el nuevo texto constitucional (Contreras, 2015; García Pino, Contreras Vásquez y Martínez Placencia, 2016: 266). De acuerdo con la Junta, las Fuerzas Armadas y Carabineros debían «garantizar la supervivencia del Estado, los principios básicos de la institucionalidad, y los grandes y permanentes objetivos de la Nación» (Mensaje del Ejecutivo a la Comisión de Estudios para la Nueva Constitución, 10 de noviembre de 1977).

Es así como el «Poder de Seguridad» puede entenderse como el conjunto de instituciones y reglas que tenían por objeto instaurar una democracia «protegida», al mando de las Fuerzas Armadas y Carabineros. El mismo texto original de la Constitución de 1980 establecía que las Fuerzas Armadas «son esenciales para la seguridad nacional y garantizan el orden institucional de la República» (Constitución Política de la República de Chile, 1980: artículo 90, inciso segundo). A su vez, en el caso de las Fuerzas de Orden y Seguridad -integradas por Carabineros y la Policía de Investigaciones-, la Constitución marcaba una radical diferencia. Como establecía su texto original, «Carabineros se integrará, además, con las Fuerzas Armadas en la misión de garantizar el orden institucional de la República» (Constitución Política de la República de Chile, 1980: artículo 90, inciso tercero). Adicionalmente, la Constitución establece que Carabineros es una institución que comparte con las Fuerzas Armadas que, «como cuerpos 
armados, son esencialmente obedientes y no deliberantes [...] profesionales, jerarquizadas y disciplinadas» (Constitución Política de la República de Chile, 1980: artículo 101, inciso tercero).

¿Cómo se configuraba este estatus de garante? Diversas disposiciones privilegiaban a las Fuerzas Armadas y a Carabineros sobre cualquier otro órgano del Estado. En primer término, la Constitución regula sus bases fundamentales en un mismo capítulo - cuestión inédita en la tradición constitucional chilena- $\mathrm{y}$, como enunciamos previamente, establece un metacerrojo de reforma para consolidar dicha regulación, al ser uno de aquellos capítulos que requieren dos tercios de los diputados y senadores en ejercicio para su modificación (Constitución Política de la República de Chile, 1980: artículo 127) (Verdugo Marinkovic, 2005: 701; Atria, 2013: 54).

Adicionalmente, se creó otra institución para canalizar este poder: el Consejo de Seguridad Nacional. Conforme a su estructura original, el Consejo de Seguridad Nacional era presidido por el presidente de la República, e integrado por los presidentes del Senado y la Corte Suprema, los comandantes en jefe de las Fuerzas Armadas y por el general director de Carabineros (Constitución Política de la República de Chile, 1980: artículo 95). Nuevamente, Carabineros gozaba de un estatus diferenciado con respecto a Policía de Investigaciones, la otra rama de las Fuerzas de Orden y Seguridad. El Consejo de Seguridad Nacional original contaba con dos facultades particularmente perniciosas para el régimen democrático: en primer lugar, tenía la facultad de autoconvocarse «a solicitud de dos de sus miembros» (Constitución Política de la República de Chile, 1980: artículo 95, inciso tercero) y podía:

Representar, a cualquier autoridad establecida por la Constitución, su opinión frente a algún hecho, acto o materia, que a su juicio atente gravemente en contra de las bases de la institucionalidad o pueda comprometer la seguridad nacional (Constitución Política de la República de Chile, 1980: artículo 96, letra b).

El Consejo de Seguridad Nacional era una pieza clave de autonomía militar-policial, para que las Fuerzas Armadas y Carabineros «no estuvieran sujetas al control político contingente de las autoridades democráticas $y$, por ende, que tuvieran un margen de acción autónomo» (Contreras, 2015: 320).

Otras reglas especiales en el texto original de la Constitución de 1980 reforzaron el estatuto constitucional de autonomía político institucional que compartían las Fuerzas Armadas y Carabineros. En primer término, los comandantes en jefe y el general director gozaban de inamovilidad en el cargo (Constitución Política de la República de Chile, 1980: artículo 93). La remoción solo era posible por decisión del presidente de la República, pero con acuerdo del Consejo de Seguridad Nacional (Constitución Política de la República de Chile, 1980: artículo 93, inciso segundo) (Peña, 2005: 718-719). Al tener este último órgano mayoría militar-policial, los incentivos para la autodefensa corporativa truncaban la subordinación al poder civil (Fuentes, 2005: 40).

En segundo lugar, tanto las Fuerzas Armadas como Carabineros tienen una regla especial de reserva de ley orgánica constitucional, que comprende los «nombramientos, 
ascensos y retiros de los oficiales» así como «las normas básicas referidas a la carrera profesional, incorporación a sus plantas, previsión, antigüedad, mando, sucesión de mando y presupuesto de las Fuerzas Armadas y Carabineros» (Constitución Política de la República de Chile, 1980: artículo 105). El hecho de que estas materias estén reguladas por leyes orgánicas constitucionales, será de vital importancia para la preservación de la autonomía de Carabineros. Como ha destacado la literatura, el quórum contramayoritario de las leyes orgánicas constitucionales es uno de los cerrojos que impiden la decisión democrática sobre las materias que han quedado bajo dicha reserva, tutelado por el control preventivo obligatorio del Tribunal Constitucional (Atria, 2013: 46-51 y 56; Jiménez, Marshall y Muñoz, 2013).

Bajo este esquema constitucional, las Fuerzas Armadas y Carabineros tenían el «monopolio» de la defensa de la Constitución (Silva Bascuñán y Silva Gallinato, 2002: 82; García Pino, Contreras Vásquez y Martínez Placencia, 2016: 266). Algunos autores consideraron que esta función no:

Podía resultar tranquilizante para la civilidad y, como muchos lo expresaron, era, en cierta forma, una invitación al golpe de Estado, tanto más si se vincula la función de "árbitro" reconocida al poder castrense con las facultades otorgadas al Consejo de Seguridad Nacional de "representar" a las autoridades su opinión frente a algún hecho, acto o materia que atente gravemente en contra de las bases de la institucionalidad (Verdugo Marinkovic, 2005: 704).

A nivel constitucional, este esquema no será reconfigurado sino tras las reformas de 2005, salvo por la reserva de Ley Orgánica Constitucional dispuesto en el artículo 105 de la Constitución.

\section{La reforma constitucional de 2005}

El «Poder de Seguridad» solo pudo ser desmantelado constitucionalmente a partir de las reformas constitucionales aprobadas en 2005. Si bien con anterioridad se habían efectuado algunas importantes reformas en 1989 -como eliminar la facultad del Consejo de Seguridad Nacional de «representar» las decisiones políticas del presidente de la República-, fue la Ley 20.050 la que eliminó buena parte de los «enclaves autoritarios» en materia de Fuerzas Armadas y Carabineros.

En primer lugar, se elimina la función exclusiva de garantía de la institucionalidad por parte de las Fuerzas Armadas y Carabineros. Esta competencia es radicada en las bases de la institucionalidad - en su artículo 6-y, particularmente, como una función general de todos los órganos del Estado, que deben someter su acción a la Constitución (García Pino, Contreras Vásquez y Martínez Placencia, 2016: 267; Contreras y Lovera, 2020: 58). La eliminación del monopolio de la defensa de la Constitución vino acompañada de la supresión de la inamovilidad de los comandantes en jefe de las Fuerzas Armadas y del general director de Carabineros (Verdugo Marinkovic, 2005; Peña, 2005). Actualmente, el presidente de la República puede remover al general director mediante 
decreto fundado e informando previamente a la Cámara de Diputados y el Senado (Constitución Política de la República de Chile, 1980: artículo 104, inciso segundo). ${ }^{6}$

Por otro lado, las reformas al Consejo de Seguridad Nacional mantuvieron a la institución, pero con cambios sustantivos:

- Al integrar al presidente de la Cámara de Diputados, la composición pasó a ser mayoritariamente civil.

- El Consejo de Seguridad Nacional deja de tener la facultad de autoconvocarse.

- Se establece que sus funciones son meramente asesoras, consultivas y no vinculantes, entre otros cambios (Contreras, 2015: 321-322).

Sin entregar nuevas atribuciones al poder civil, estas reformas relegaron al Consejo de Seguridad Nacional, en la práctica, a ser un órgano de rango constitucional meramente simbólico (Consejo de Seguridad Nacional de Chile, 2019).?

Las reformas fueron centrales para desarticular el carácter tutelar de la democracia que era compartido entre las Fuerzas Armadas y Carabineros. La eliminación del «Poder de Seguridad», sin embargo, no supuso necesariamente una completa subordinación de estas con el poder civil democráticamente electo (Contreras y Salazar, 2020). El análisis de esta autonomía en la policía uniformada — garantizada normativamentees lo que se analiza a continuación.

\section{La autonomía de Carabineros}

El concepto de autonomía de las policías es una cuestión altamente discutida en la ciencia política, más que en el derecho. En las democracias latinoamericanas, la autonomía policial determina el ejercicio de violencia, las violaciones a los derechos humanos y los hechos de corrupción (Flom, 2019). Entre nosotros, Frühling (1999: 68) ha sostenido que, durante la dictadura militar, las policías acentuaron sus diferencias culturales y políticas. En ese contexto, Carabineros fue parte del régimen político e incrementó su autonomía «institucional» y «corporativa», especialmente a través de las normas constitucionales.

Dammert (2019: 96), por otro lado, y construyendo sobre la clásica discusión de

6. Así lo hizo el presidente Sebastián Piñera para destituir al general director Hermes Soto, como consecuencia de la pérdida de confianza, ante la comisión de diversos delitos e irregularidades cometidos por miembros de Carabineros. Esta atribución exclusiva se ejerció por medio del Decreto 1.555 del 21 de diciembre de 2018 .

7. Quizás la última convocatoria del Consejo de Seguridad Nacional sea un caso representativo de su carácter simbólico. El 7 de noviembre de 2019, el presidente de la República convocó al Consejo de Seguridad Nacional debido a los problemas de desórdenes públicos en relación con el denominado «estallido social» que Chile vivió a partir del 18 de octubre del mismo año. En dicha oportunidad, el contralor general de la República manifestó que no le "parecía» la convocatoria realizada, ya que, en su opinión, «no habría argumentos para entender que estamos frente a un problema de seguridad nacional, ya que aquí hay un problema de orden público, lo que amerita otro tipo de soluciones». 
Huntington y Janowitz, analiza el control civil desde un punto de vista objetivo y subjetivo. La autora plantea que la necesidad de control de las policías requiere "profesionalizar el trabajo policial (control civil objetivo) y hacerlo más abierto al mundo civil (control civil subjetivo)».

En el ámbito del derecho público, la noción de autonomía de las instituciones se ha construido sobre la base de la independencia de los órganos del Estado para adoptar sus decisiones y ejercer sus funciones (García Pino, Contreras Vásquez y Martínez Plascencia, 2016: 87). Con respecto a las Fuerzas Armadas $-y$, aquí, por equiparación, a Carabineros-, el concepto de autonomía necesariamente se conecta con la subordinación de los cuerpos armados al poder democráticamente electo (Contreras y Salazar, 2020). Sobre dicha base, la idea de «autonomía» de Carabineros podría entenderse como las condiciones o factores jurídicos que habilitan una independencia de la institución con respecto a las autoridades civiles, tanto para el ejercicio de sus funciones como con respecto al control que debiese pesar sobre estas.

Vinculado con lo anterior, las reformas constitucionales de 2005 adecuaron, en clave democrática, la relación del poder político con las instituciones armadas, pero no lograron desarticular la arquitectura normativa que resguardaba y privilegiaba a Carabineros. En este sentido, si bien todo órgano estatal requiere de ciertos niveles de autonomía para cumplir cabalmente las funciones que le han sido encomendadas, vemos, en el caso de Carabineros, la persistencia de altos grados de una exacerbada autonomía normativa.

Para ello, es fundamental analizar la Constitución, las leyes orgánicas constitucionales y otras leyes de importancia que instauran el régimen de autonomía normativa de Carabineros, el cual es equiparable al de las Fuerzas Armadas.

El vigente capítulo XI de la Carta Fundamental establece un tratamiento específico para Carabineros, en consonancia con la Ley 18.961 de 1990 — su ley orgánica constitucional,$-{ }^{8}$ al delimitar las funciones específicas de esta institución policial en nuestro ordenamiento jurídico. Este régimen de excepcionalidad se fortalece por lo dispuesto en el artículo 21, inciso segundo, de la Ley Orgánica Constitucional de Bases Generales de la Administración del Estado (Ley 18.575, 1986), ${ }^{9}$ al reconocer márgenes de desconcentración funcional (Cordero, 2015: 122-123) destinados a regular materias relacionadas con el funcionamiento y la organización basal de dicha institución policial a través de la indicada estructura normativa. Esto, a pesar de que Carabineros es un organismo que pertenece a la Administración del Estado, como lo señala el artículo 1, inciso segundo, de la Ley Orgánica Constitucional de Bases Generales de la Administración del Estado, al instituir la regla general sobre estos para la regulación de sus aspectos organizacionales, de contratación, control de su actividad, entre otras, en virtud del artículo 38, inciso primero, de la Constitución.

8. Para el caso concreto de la Policía de Investigaciones, se trata del Decreto Ley 2.460 de 1974 (cuya última modificación se concretó en 2018), que dicta Ley Orgánica de Policía de Investigaciones de Chile.

9. Actualmente, refundido en el Decreto con Fuerza de Ley 1-19653 del Ministerio Secretaría General de la Presidencia de 2001. 
Además, la preparación de parte importante y sustancial de esta estructura normativa se realizó durante los últimos años de la dictadura militar, la que contó con la colaboración directa de civiles tecnócratas afines al régimen, buscándose implementar un alto grado de autonomía de Carabineros en su relación con el poder civil, protegiéndose su carácter profesional y generándose una serie de estatutos especiales y diferenciados con respecto al resto de los organismos de la Administración del Estado (Agüero, 2003: 256-257).

No obstante, sostenemos que tanto la Constitución, la Ley 18.961 y la Ley 20.502 prescriben que esta fuerza pública depende del Ministerio del Interior y Seguridad Pública, ${ }^{10}$ en su calidad de colaborador directo e inmediato del presidente de la República en asuntos relativos al orden público y la seguridad pública interior. ${ }^{11}$ Por tanto, y a pesar del régimen descrito, la señalada dependencia jerárquica de la institución policial conlleva el cabal cumplimiento de los principios de obediencia y no deliberancia, por expreso mandato constitucional y legal orgánico constitucional, para con la mencionada autoridad política civil.

Por tanto, identificamos la existencia de dos niveles de funcionamiento autónomo normativo en Carabineros: la político-institucional, referida al rol que cumple (y cumplió) la institución policial en nuestro sistema político y jurídico; y la operativa funcional.

\section{La autonomía político-institucional de Carabineros}

Las reformas constitucionales al «Poder de Seguridad» no han generado la subordinación suficiente de las fuerzas estatales al poder civil democrático y no eliminaron totalmente la autonomía político institucional reconocida a Carabineros, por lo que el reconocimiento de este ámbito sigue siendo relevante (Heiss y Navia, 2007).

La persistencia de todos los elementos normativos señalados anteriormente - en particular los referentes a la dimensión constitucional- permiten sostener la vigencia de este criterio, debido al inusitado y radical rol reconocido en el texto original de la Constitución a las fuerzas estatales como garantes de la institucionalidad. De esta manera, la autonomía normativa político-institucional reconocida buscaba asegurar el cumplimiento del citado rol tutelar de forma independiente y sin controles por parte del poder civil electo democráticamente, constituyéndose en un componente institucional de suma trascendencia para el desarrollo de la democracia semisoberana ( $\mathrm{Hu}-$ neeus, 2015: 187-190). ${ }^{12}$

10. Hasta antes de la aprobación de dicha ley, en 2011, Carabineros dependía jerárquicamente del Ministerio de Defensa Nacional.

11. Es importante destacar que el artículo 24, inciso segundo, de la Constitución, indica que la conservación del orden público en el interior de la República es una de las atribuciones esenciales del presidente de la República, la que debe cumplirse de acuerdo con la Carta Fundamental y las demás leyes relacionadas.

12. Complementario a esta reflexión, en el capítulo sexto de su libro La democracia semisoberana: Chile después de Pinochet, Carlos Huneeus destaca el fundamental rol que cumplió Augusto Pinochet en el siste- 
Junto con las Fuerzas Armadas, se mantiene el tratamiento constitucional de un capítulo exclusivo en la Constitución, que regula elementos básicos organizacionales, funcionales y la designación de su mando superior, y establece una reserva de ley orgánica constitucional. En síntesis, la mantención del mencionado capítulo es un claro ejemplo de la importancia que cumple y ha cumplido Carabineros - y el resto de los institutos armados- en el sistema político nacional, en consideración de las funciones y competencias atribuidas a la citada fuerza policial, previo a las señaladas reformas constitucionales, y a las que actualmente se encuentran vigentes en el texto constitucional.

En virtud de las críticas recientes al actuar de la policía - recogidas en informes y en procesos judiciales en curso en contra de uniformados y exfuncionarios policiales-, es necesario implementar una agenda de transformación institucional. Sin embargo, existe una dificultad objetiva dado los quórums de aprobación de normas para reformar el estatuto constitucional de la policía y la regulación de varias materias por leyes orgánicas constitucionales.

\section{La autonomía operativa funcional de Carabineros}

Este ámbito de autonomía normativa se explica en función del establecimiento de aspectos regulados por leyes orgánicas constitucionales; materias protegidas bajo causales especiales de reserva o secreto; regulaciones especiales que se diferencian del régimen general de la Administración del Estado - como el caso de los bienes inmuebles-; y la jurisdicción penal policial y su régimen administrativo disciplinario.

Antes de entrar al análisis de estas categorías, es conveniente destacar cómo la equiparación militar de Carabineros con las Fuerzas Armadas plantea una serie de diferencias con la otra rama de las Fuerzas de Orden y Seguridad Pública, la Policía de Investigaciones de Chile. A modo ejemplar, de la revisión del Decreto Ley 2.960 del 24 de enero de 1979 - Ley Orgánica de la Policía de Investigaciones- se observa que dicha norma aborda únicamente aspectos referidos a su organización, misión y funciones específicas; normas especiales del procedimiento penal; a la Dirección General de la institución; y disposiciones varias sobre nombramiento y selección del personal, ascensos, identificación, delitos especiales agravados en contra del personal, exenciones de responsabilidad penal.

Por su parte, la Ley 18.961 aborda una mayor cantidad de materias sometidas a reserva de ley orgánica, las que serán revisadas a continuación. Además, no son aplicables para la Policía de Investigaciones el Decreto Ley 1277 de 1975 sobre los Fondos Rotativos de Abastecimiento (FORA), ni cuentan con una ley especial para la construcción de obras de exclusivo carácter policial de la institución, las que sí se establecen para las Fuerzas Armadas y Carabineros.

ma político transicional nacional, apoyado por todos los elementos constitucionales señalados, lo que permite graficar el rol de veto que cumplió el dictador (y por extensión, las ramas castrenses y Carabineros) mientras ejercía el cargo de comandante en jefe del Ejército y senador vitalicio. 


\section{Aspectos regulados por leyes orgánicas constitucionales}

La Ley 18.961 — publicada el 7 de marzo de 1990, cuatro días antes de que asumiera el presidente electo democráticamente- concretiza la reserva de ley del artículo 105 de la Constitución. En dicha norma, se desarrollan aspectos referidos a la organización general de la institución; la carrera profesional de su correspondiente personal, el funcionamiento de la antigüedad y mando, ejercido por el general director; aspectos previsionales y de seguridad social; y normas generales sobre el régimen presupuestario de la institución, estableciendo niveles concretos de autonomía operativa funcional, al decidirse aspectos institucionales cruciales por parte del general director y solo informadas al Ministerio del Interior y Seguridad Pública. Todo esto, según el artículo 3, letra b, de la Ley 20.502 de 2011. ${ }^{13}$

$\mathrm{Al}$ respecto, afirmamos que esta estructura normativa le permitió a Carabineros conservar diversos ámbitos de privilegios, en comparación con otros organismos públicos, y asegurar una actuación autónoma en el cumplimiento de las atribuciones conferidas a la institución policial. Para la aprobación, modificación o derogación de una ley orgánica constitucional, se requiere el voto favorable de 4/7 de diputados y senadores en ejercicio. Según el artículo 109 bis de la Ley 18.799 de 1989, dicho quórum se hacía más complejo de alcanzar en el contexto del anterior sistema electoral para la elección de los congresales, el denominado «sistema binominal»; ${ }^{14}$ en atención a la redacción original de la Constitución, que consideraba la existencia de senadores designados, exuniformados que representaban directamente los intereses de instituciones armadas, $\mathrm{y}$ vitalicios; ${ }^{15} \mathrm{y}$ con un control preventivo obligatorio por parte del Tribunal Constitucional de los proyectos de leyes sobre estas materias, dificultaron la implementación de reformas en el sector. Este escenario alteró el proceso de deliberación democrática: cualquier cambio regulatorio debía contar, necesariamente, con el acuerdo de quienes respaldaron el accionar militar y policial, durante de la dictadura. A pesar de las diversas reformas legales introducidas durante los últimos treinta años a la Ley 18.961, dichos cambios no abordaron — sino que mantuvieron- estos niveles de operación autónoma de la fuerza policial y la debilidad del poder civil para efectuar una adecuada dirección y control de esta.

13. Estas modificaciones de información al Ministerio del Interior y Seguridad Pública fueron introducidas por la Ley 20.801 de 2014, que aumentó las plantas del personal de Carabineros de Chile y modificó la Ley 20.502 y la Ley 18.961.

14. Este artículo, en su redacción original, estuvo vigente hasta 2015, cuando fue modificado por la Ley 20.840. Sustituye el sistema electoral binominal por uno de carácter proporcional inclusivo y fortalece la representatividad del Congreso Nacional.

15. Ambos tipos de senadores fueron eliminados tras la reforma constitucional del 2005. 


\section{Organización general de la institución}

El artículo 3 de la Ley 18.961 atribuye a Carabineros la determinación de los servicios policiales que considere necesarios para el cumplimiento de sus competencias. ${ }^{16}$ Esto implica labores preventivas, investigación policial, protección del presidente de la República y de otros jefes de Estado, vigilancia de fronteras, tareas de colaboración internacional, y la fiscalización y control tanto de la seguridad como de la vigilancia privada. La disposición permite la dictación de normas y reglamentos internos al general director para el cumplimiento de dichas competencias, las que deben ser informadas en forma global y, al menos, semestralmente al Ministerio del Interior y Seguridad Pública. Además, el artículo 4 establece la colaboración permanente de Carabineros de auxilio público a las autoridades judiciales y administrativas, e investigativas con el Ministerio Público.

Por tanto, y para cumplir todas estas finalidades, se autoriza expresamente al general director para contratar personal temporal y de diversos niveles profesionales cuando las necesidades del servicio lo ameriten, informando en forma semestral al Ministerio del Interior y Seguridad Pública, según lo señalado en el artículo 7. Todas estas decisiones son adoptadas directa y unilateralmente por la institución policial, en virtud del reconocimiento expreso de las señaladas potestades en dicha norma, sin que pueda realizarse un efectivo control de estas por parte del Ministerio del Interior y Seguridad Pública en su calidad de superior jerárquico.

\section{Carrera profesional ${ }^{17}$}

A pesar de tratarse de una institución jerarquizada y con un régimen disciplinario ad hoc, el artículo 8 de la Ley 18.961 prescribe el establecimiento de un sistema técnico reglado para el personal policial, el que presenta ciertas particularidades. Dicha ley orgánica constitucional replica lo establecido en el artículo 102 de la Constitución, al señalar que el ingreso a las respectivas plantas debe efectuarse - por regla general- a través de las propias escuelas institucionales, según el artículo 9, inciso segundo, de la Ley 18.961, complementándose con la autonomía de la institución para la determinación de los procesos de formación, perfeccionamiento y capacitación técnica policial, los que se encuentran financieramente asegurados en la Ley de Presupuestos. Carabineros define sus planes y programas de estudio en sus escuelas matrices - los que son considerados como Instituciones de Educación Superior- ${ }^{18}$ pudiendo otorgar grados académicos y

16. En concordancia con el artículo 52, letra b, de la Ley 18.961 de 1990.

17. En esta materia, la Ley 18.961 se complementa con el Decreto 412 de 1992, que es el texto refundido, coordinado y sistematizado del Decreto con Fuerza de Ley 2 de 1968, Estatuto del Personal de Carabineros de Chile.

18. La Escuela de Carabineros General Carlos Ibáñez del Campo, destinada a formar a los oficiales de la institución, es la única entidad educativa de Carabineros que se encuentra acreditada por la Comisión Nacional de Educación, solo desde 2019. 
títulos técnicos y profesionales equivalentes a los que expiden las demás instituciones de educación superior reconocidas por el Estado. Todo esto según los artículos 17 y siguientes de la Ley 18.961. ${ }^{19}$

Con respecto a los nombramientos, ascensos, reincorporaciones, llamados al servicio y retiros del personal policial, estos se efectúan mediante decreto supremo cursados a través del Ministerio del Interior y Seguridad Pública y a proposición del general director, esto último, como requisito fundamental en dicha decisión, asegurando el carácter jerarquizado y mando en la institución, según el artículo 10 de la Ley 18.961.

Sobre esta temática, resaltamos la especial atribución prescrita en el artículo 16 de la presente ley, en que la citada autoridad policial propone al presidente de la República (personal de nombramiento supremo) —e informa al Ministerio del Interior y Seguridad Pública - y también dispone (personal de nombramiento institucional) la llamada al servicio activo de exfuncionarios en retiro absoluto por necesidades institucionales, fijándose por decreto supremo el número de empleos y grados del personal disponible.

En relación con la calificación del personal, se establece un sistema anual para medir su desempeño profesional en virtud de lo dispuesto en su Estatuto del Personal. En dicha norma se considera que, salvo los oficiales generales, serán calificados por medio de tres juntas: la Junta Calificadora de Méritos, la Junta Calificadora de Méritos y de Apelaciones, y la Junta Superior de Apelaciones, cuyos resultados son soberanos y pueden determinar las listas de ascensos, formación y retiro del personal policial sobre la base de antigüedad y mérito. Ahora bien, existen niveles de opacidad en la determinación de dichas instancias evaluadoras del personal que dificultan un adecuado control de las decisiones adoptadas por estas. Se trata de una materia que requiere ser analizada detalladamente para la satisfacción y el cumplimiento de un régimen de buena administración y buen gobierno, bajo el paradigma de la probidad administrativa, la transparencia y tanto el respeto como la promoción de los derechos fundamentales, de los procedimientos administrativos relacionados con la carrera del personal policial (Ponce Solé, 2019).

Por tanto, en la carrera profesional del personal policial, el general director adopta decisiones discrecionales en materias tan diversas como el ingreso y la reincorporación al servicio del personal en retiro temporal; para el cambio de escalafón; el pase para el ascenso de los oficiales generales, dispensar requisitos de ascenso en casos determinados y mantener en la institución a coroneles de Orden y Seguridad no ascendidos; las comisiones de servicio en territorio nacional como en el extranjero; y la autorización de permanencia voluntaria en la fuerza hasta 35 años de servicio institucional (y 38 años de manera forzosa); entre otras. Todas estas decisiones son adoptadas directa y unilateralmente por la institución policial, en virtud del reconocimiento expreso de las señaladas potestades en dicha norma, sin que pueda realizarse un efectivo control de

19. En este sentido, el artículo 20, inciso final, autoriza al general director a celebrar convenios con instituciones públicas o privadas, nacionales o extranjeras, informando semestralmente al Ministerio del Interior y Seguridad Pública. 
estas por parte del Ministerio del Interior y Seguridad Pública en su calidad de superior jerárquico.

\section{Previsión y seguridad social}

La Ley 18.961 prescribe un sistema autónomo de reparto solidario que considera la progresión de la carrera profesional policial, en el que se entregan varios beneficios previsionales, como pensiones de retiro y montepío, desahucios y prestaciones generales de seguridad social y salud. El sistema es administrado por la Dirección de Previsión de Carabineros de Chile y se financia por:

- El aporte que efectúa el personal adscrito a dicho régimen mediante el pago de imposiciones, cotizaciones y aportes diversos.

- Aportes de empleadores.

- El Fisco, quien ingresa anualmente la mayor parte de los fondos suficientes para cubrir el pago de los beneficios (Benavides y Jones, 2012; CIEDESS, 2017: 24-26; Ley 18.961, 1990: artículo 79). ${ }^{20}$

Relativo al personal que se inutilizare, el general director está autorizado para definir los correspondientes grados de invalidez y la capacidad de continuar o no en el servicio por parte del personal policial accidentado, por lo que afirmamos que los mayores márgenes de decisiones discrecionales autónomas sobre la materia se encuentran en la determinación de estos beneficios, según los artículos 64 y siguientes de la Ley 18.961. Estas decisiones son adoptadas directa y unilateralmente por la institución policial, sin que pueda realizarse un efectivo control de estas, por parte del Ministerio del Interior y Seguridad Pública, en su calidad de superior jerárquico.

Ahora bien, incluso considerando las particularidades propias de la carrera funcionaria en Carabineros, dicho sistema ha sido fuertemente cuestionado por las patentes diferencias con el régimen de previsión y seguridad social de aplicación general. En comparación con la ciudadanía en general, ante similares márgenes de cotización, las pensiones promedio de los funcionarios de Carabineros son entre cuatro y siete veces superiores al resto de la población —el promedio de pensión percibida vía Dirección de Previsión de Carabineros de Chile es de \$874.024 a 2016 (CIEDESS, 2017: 24).

20. El artículo citado asegura el pago de pensiones iniciales en un porcentaje que no será inferior al $75 \%$ de estas, considerando reajustes o aumento de dichos beneficios. Al respecto, el aporte fiscal libre para cumplir con esta obligación legal, establecido en la partida 15, capítulo 14, programa 1, subtítulo 9, ítem asignado 1, para la Ley de Presupuesto del Sector Público de los 2018 y 2019 ejecutado, fue de 638.117.498 y 688.914.362 respectivamente; y lo aprobado en 2020 asciende a 714.642.678. Cifras en miles de pesos chilenos. 


\section{Régimen presupuestario}

La Ley 18.961 determina una serie de preceptos referentes al régimen presupuestario de Carabineros que se diferencia del sistema general de administración financiera pública, aplicable para el resto de los organismos de la administración del Estado, lo que facilita un importante nivel de autonomía en el funcionamiento operativo de esta fuerza pública.

Con respecto al mecanismo ordinario de aporte fiscal, es decir, la Ley de Presupuestos, plantea diversas particularidades. En primer lugar, según el artículo 86, inciso primero, de la Ley 18.961, se establece una relación directa entre el ministro del Interior y Seguridad Pública y el general director, en que este último comunica las necesidades institucionales, ${ }^{21}$ las que, sin una evaluación detallada por parte del poder civil, son enviadas al Ministerio de Hacienda, procediendo a aplicarse las normas generales sobre Administración Financiera del Estado, según los artículos 97 y 90 de la misma ley. ${ }^{22}$ Como segundo aspecto, se eleva a rango orgánico constitucional el aseguramiento del mayor aporte fiscal a la institución policial ante la aprobación de nuevas funciones o el cumplimiento de labores en situaciones de excepcionalidad, ya sea por vía presupuestaria o por la disponibilidad de ingresos adicionales, según el artículo 86, inciso 2 y final, de la Ley 18.961. En tercer lugar, y según el artículo 88 de la Ley 18.961, el establecimiento de un piso mínimo de financiamiento presupuestario en el gasto del personal policial reajustable, cuya base consiste en el mismo gasto utilizado en el ejercicio de 1989. Ahora bien, con la aprobación de la Ley 21.211 de 2020, sobre información y rendición de cuentas de gastos reservados, se deroga el anterior piso mínimo que esta ley orgánica constitucional consideraba, relativo al monto disponible para los gastos reservados que disponía el general director en el cumplimiento de las atribuciones de la fuerza policial, como consecuencia de las sendas investigaciones judiciales llevadas a cabo por el mal uso de estos recursos públicos al interior de las Fuerzas Armadas y Carabineros. Por último, se autoriza la rendición reservada al Ministerio del Interior y Seguridad Pública de aquellos gastos presupuestarios calificados como netamente policiales, cuya determinación queda atribuida a proposición efectuada por el general director según el artículo 89 de la Ley 18.961.

Vinculado con los demás recursos que contempla la ley, es menester destacar lo referente a la inversión de fondos propios, según el artículo 52, letra o, de la Ley 18.961, en moneda nacional o extranjera, como son los Fondos Rotativos de Abastecimiento (FORA) (Decreto Ley 1.277, 1975). Esta ley permite, a la fuerza policial, contar con cuentas bancarias para realizar una serie de operaciones financieras para ingresar o

21. Artículo relacionado con el artículo 52, letra d, de dicha ley, referente a las facultades del general director en el ejercicio del mando de la fuerza policial.

22. En este punto, particular atención concita el hecho de que cualquier traspaso de recursos entre subtítulos debe concretarse por decreto supremo a proposición del general director. Ahora bien, las normas principales relacionadas son: i) la Ley 20.128 de 2006, sobre Responsabilidad Fiscal, que fija la regla de balance estructural; y ii) el Decreto Ley 1.263 de 1975, Orgánico de Administración Financiera del Estado. 
gastar recursos obtenidos a partir de los respectivos sistemas de abastecimiento de la institución, con la posibilidad de ejecutar dichos montos más allá de un año calendario presupuestario, por medio de varias exenciones y beneficios aduaneros y tributarios, según el artículo 91 de la Ley 18.961.

\section{Materias protegidas bajo causales de reserva o secreto}

En términos generales, todos los órganos del Estado están sujetos al principio constitucional de publicidad, establecido en el artículo 8, inciso segundo, de la Carta Fundamental. Dicho precepto establece que «son públicos los actos y resoluciones de los órganos del Estado, así como sus fundamentos y los procedimientos que utilicen». A continuación, establece cuatro causales de reserva o secreto que deben ser establecidas por ley de quórum calificado, a saber: afectar el «debido cumplimiento de las funciones de dichos órganos, los derechos de las personas, la seguridad de la Nación o el interés nacional». Nótese que el control del orden público o la seguridad pública no está en el catálogo de excepciones. Carabineros, al ser un órgano del Estado, está sujeto al principio constitucional. Sin embargo, también tiene un régimen especial de reglas con respecto a la reserva o secreto de información, equiparado normativamente al de las Fuerzas Armadas. En otros términos, el secreto policial se asimila normativamente al secreto militar. Esta homologación es constatable a partir de las siguientes normas.

En primer lugar, el artículo 89 de la Ley 18.961 dispone que la rendición de los «gastos netamente policiales»-calificados como tales en la Ley de Presupuestos- debe hacerse de forma reservada al Ministerio del Interior y Seguridad Pública a través de la Subsecretaría del Interior. La Ley 20.801 aumentó las plantas de Carabineros e incorporó la exigencia de informar reservadamente al Ministerio, agregando que esta obligación es «sin perjuicio de las obligaciones de rendición e información existentes en otros cuerpos legales».

Originalmente, la disposición contenía, además, la regulación de los gastos reservados de la institución con una regla de «piso», esto es, asegurando un mínimo de recursos fijados a partir de 1989. El ahora derogado inciso 2 del artículo 89 establecía que «los gastos reservados, cuyos montos serán fijados anualmente, no podrán ser inferiores a los decretados inicialmente para tal efecto en 1989, actualizados mediante el procedimiento establecido en el artículo 88 de la presente ley». Sin embargo, este régimen ha sido reformado en 2020 a través de la Ley 21.211, sobre información y rendición de cuentas de gastos reservados. La nueva regulación, en síntesis, fijó la finalidad de los gastos reservados, incorporó un control político a nivel ministerial y eliminó el «piso» presupuestario de estos gastos.

Sin perjuicio de estos avances, las mayores áreas de opacidad son aseguradas por reglas de secreto que no han sido alteradas hasta el día de hoy. El artículo 436 del Código de Justicia Militar es, quizás, la regla operativa de secreto más relevante al respecto. Esta norma no es original al Código de Justicia Militar y fue incorporada a partir de la reforma de la Ley 18.667 de 1987. El artículo 436 del Código dispone que «se entienden por 
documentos secretos aquellos cuyo contenido se relaciona directamente [...] el orden público interior» y lista cuatro materias de reserva: «plantas y dotaciones de Carabineros; planos o instalaciones de recintos policiales y planes de operación o servicio; documentos concernientes a armas; $\mathrm{y}$ documentos sobre equipos y pertrechos policiales».

La norma es previa a la reforma constitucional de 2005, que introdujo el artículo 8 citado (Contreras, 2014: 55-63). Si bien la norma original se refería únicamente al secreto militar, la vigente redacción es una excepción que califica en términos amplios el secreto en función de la seguridad de la Nación, homologándolo al orden público interior y equiparando lo militar con lo policial. Así, las plantas, dotaciones y personal de Carabineros son secretas, al igual que las de las Fuerzas Armadas. Otro tanto ocurre con recintos policiales, planes de operación, armas, equipos y pertrechos. Para el Código de Justicia Militar, por ejemplo, el equipamiento policial tiene el mismo régimen de reserva que el equipamiento de guerra.

Finalmente, tanto Carabineros como las Fuerzas Armadas gozan de un régimen de gestión documental único, que fortalece la autonomía y la discrecionalidad en el manejo de la información y de los archivos de estas instituciones. En enero de 1989, la Junta Militar dicta la Ley 18.771, creando una excepción al régimen general de archivos de la Administración del Estado, contenido en el DFL 5.200 de 1929. Dicha ley incorporó un inciso final al artículo 14 del DFL 5.200, y fijó una facultad especial de archivo y de destrucción de información para el Ministerio de Defensa Nacional, las Fuerzas Armadas, las Fuerzas de Orden y Seguridad, y para los organismos dependientes de dicho ministerio o que se relacionan con el presidente de la República a través de este. Esta última pieza forma parte importante del marco legal e institucional que amparó las violaciones a los derechos humanos y la impunidad. Esto fue registrado por el Informe Rettig (Comisión Nacional de Verdad y Reconciliación, 1991: 67).

\section{Regulaciones especiales sobre bienes inmuebles de Carabineros}

La administración de bienes públicos inmuebles es un caso concreto que ejemplifica el nivel de autonomía operativa funcional reconocida a Carabineros, bajo un marco normativo excepcional, en relación con el resto de la administración pública. Esta se divide en tres:

- La facultad de adquirir y enajenar bienes inmuebles determinados.

- Las normas especiales para la construcción de recintos policiales.

- La existencia del Patrimonio de Afectación Fiscal en la Dirección de Bienestar de Carabineros de Chile. ${ }^{23}$

23. En este sentido, el artículo 52, letra o, de la Ley 18.961, faculta al general director para disponer la inversión de fondos que se destinen por ley a la Institución y de los recursos que se obtengan por enajenaciones y ventas a que se refieren las letras anteriores. Además, estos últimos recursos constituirán ingresos propios de Carabineros y no ingresarán a rentas generales. 
Sobre el primer aspecto, el artículo 99 del Decreto Ley 1.939 de 1977, normas sobre Adquisición, Administración y Disposición de Bienes del Estado, mantiene vigente el Decreto Ley 1.113 de 1975 - que fija normas para la adquisición de bienes raíces por las Fuerzas Armadas y otras disposiciones legales que regulan la adquisición, administración y disposición de bienes inmuebles para Carabineros. Dicho decreto de ley autoriza a la Dirección Logística de la fuerza policial para adquirir o enajenar, ${ }^{24}$ a cualquier título, bienes raíces en representación del fisco. Estos terrenos son complementarios a los destinados por parte del Ministerio de Bienes Nacionales, y los fondos obtenidos podrán ser utilizados para el estudio, planeamiento, proyección, construcción, demolición, ampliación, reparación, conservación, reposición o adquisición de bienes destinados al uso de la institución. Si no son usados durante el año calendario, estos fondos igualmente quedarán a disposición de esta para su uso en los fines indicados, los cuales estarán libres del pago de impuestos o derechos.

En segundo lugar, esta norma debe ser complementada con lo dispuesto en la Ley 18.785 de 1989, que establece normas para construcción de obras de exclusivo carácter policial de Carabineros de Chile, que permite un estatuto diferenciado para la planificación, estudio, proyección, construcción, demolición, ampliación, reparación, conservación y explotación para obras de carácter policial. Dicha norma autoriza al general director a realizar una serie de gestiones destinadas al cumplimiento de los mencionados fines, como proponer posibles expropiaciones, contratar estudios y proyectos de obras, y ejecutar y fiscalizar el cumplimiento de las obras por medio de la Dirección Logística de la institución. Se autoriza la apertura y mantención de una cuenta bancaria con carácter exclusivo para estos fines, usándose la totalidad de los fondos recibidos por la vía presupuestaria o por otros orígenes de forma exclusiva en labores vinculadas a obras de carácter policial. En el caso de no usar los fondos en un año presupuestario calendario, estos quedarán a disposición de la citada fuerza y podrán ser empleados en los señalados fines en el siguiente ejercicio presupuestario.

En relación con la tercera materia, la Ley 18.713 de 1988 - que establece un nuevo estatuto de la Dirección de Bienestar de Carabineros de Chile-, prescribe a este organismo la finalidad de proporcionar al personal las prestaciones que tiendan a promover una adecuada calidad de vida que contribuya a su bienestar y al de sus familias, principalmente para fines educativos, habitacionales y recreacionales. De esta manera, se crea el Patrimonio de Afectación Fiscal, para cumplir cabalmente con dichos fines, y está compuesto de bienes y recursos proveniente de operaciones comerciales y financieras de diversa índole.

Esta ley prescribe que dicha repartición policial actuará como persona jurídica autorizada para celebrar una gran cantidad de actos y contratos, operaciones financieras y bancarias sobre los bienes que componen el Patrimonio de Afectación Fiscal, tendiente a conseguir y mantener las condiciones de bienestar social mencionadas. A su vez, determinan sus presupuestos anualmente, previa autorización de la autoridad respectiva;

24. Atribución incluida por la Ley 18.872 de 1990. 
y los fondos no invertidos dentro del presupuesto anual pueden ser usados al año siguiente. Además, las prestaciones otorgadas por la Dirección de Bienestar quedan liberados de los impuestos al valor agregado, a la renta, de timbres y estampillas, y exentos del pago del impuesto territorial.

En conclusión, todas estas decisiones son adoptadas directa y unilateralmente por la institución policial, sin que pueda realizarse un efectivo control de estas por parte del Ministerio del Interior y Seguridad Pública en su calidad de superior jerárquico.

\section{Jurisdicción penal policial y el régimen administrativo disciplinario}

Como último ámbito que ejemplifica los niveles de autonomía operativa-funcional, corresponde señalar a la jurisdicción penal policial y el régimen disciplinario reconocido a Carabineros.

Carabineros es considerada una institución militar a efectos de estar sometida a un régimen jurisdiccional especial, regulado en el Código de Justicia Militar. Así lo reconoce expresamente el artículo 6 de este cuerpo legal, al prescribir la extensión del carácter militar a los efectivos pertenecientes a esta fuerza policial, sean estos funcionarios de planta, personal llamado al servicio activo, personal de reserva llamado al servicio activo y los alumnos pertenecientes a sus escuelas matrices (Código de Justicia Militar de Chile, 1944: artículo 6). ${ }^{25}$

Desde el retorno a la democracia, han existido cambios en el alcance de la competencia de los tribunales militares. En este sentido, destacamos la aprobación de las Leyes 19.047 de 1991, y 20.050 de 2005; pero fueron las modificaciones impulsadas por las Leyes 20.477 , de 2010, y 20.968, de 2016, las que restringieron la competencia de estos tribunales al establecer que, cuando la víctima o el imputado sean personas civiles y/o menores de edad, serán competentes para el conocimiento de estos hechos los tribunales ordinarios con competencia en lo penal. Este cambio influyó ostensiblemente en el tratamiento de delitos de común ocurrencia en labores policiales, como el maltrato de obra de Carabineros (Código de Justicia Militar de Chile, 1944: artículo 416 bis), apremios ilegítimos (Código Penal de la República de Chile, 1875: artículo 150 D) y violencias innecesarias (Código de Justicia Militar de Chile, 1944: artículo 330). ${ }^{26}$

25. «Para los efectos de este Código y de las demás leyes procesales y penales pertinentes, se considerarán militares los funcionarios pertenecientes a las Fuerzas Armadas y de Carabineros de Chile, constituidos por el personal de planta, personal llamado al servicio y el personal de reserva llamado al servicio activo. Además, se considerarán militares los soldados conscriptos; los oficiales de reclutamiento; las personas que sigan a las Fuerzas Armadas en estado de guerra; los prisioneros de guerra, que revistan el carácter de militar, los cadetes, grumetes, aprendices y alumnos regulares de las Escuelas Institucionales y de Carabineros de Chile. Con todo, los menores de edad siempre estarán sujetos a la competencia de los tribunales ordinarios, de acuerdo con las disposiciones de la ley 20.084, que establece un sistema de responsabilidad de los adolescentes por infracciones a la ley penal. Para efectos de determinar la competencia de los tribunales militares, la calidad de militar debe poseerse al momento de comisión del delito».

26. Según lo comunicado por el Ministerio Público el 31 de enero de 2020, entre el 18 de octubre y el 31 de diciembre de 2019, en el contexto de la crisis social y dentro de las principales variaciones porcentuales 
No obstante, tanto la arquitectura de la justicia militar como el procedimiento penal militar se encuentran al debe en materia de cumplimiento de los estándares internacionales de derechos humanos, definidas por la Corte Interamericana de Derechos Humanos en el caso Palamara Iribarne con Chile (Sentencia de la Corte Interamericana de Derechos Humanos, Fondo, reparaciones y costas, Ser. C, 135, 22 de noviembre de 2005) y, posteriormente, reiteradas en el caso Almonacid Arellano con Chile (Eva Parada, 2006; Aguirre, 2007; Díaz Tolosa, 2007; Contreras, 2011: 209-226). En ambos casos, el estándar interamericano restringe la discrecionalidad estatal de configurar una justicia militar solo con respecto a militares y para la punición de lesiones de bienes jurídicos estrictamente militares (Sentencia de la Corte Interamericana de Derechos Humanos, Fondo, reparaciones y costas, Ser. C, 135, 22 de noviembre de 2005: sección 256). Esta definición excluye, en primera instancia, la amplitud de competencia objetiva de la justicia militar para incluir a policías por delitos policiales.

Sobre el segundo aspecto, el artículo 36 de la Ley 18.961 autoriza el ejercicio de la potestad disciplinaria por parte del general director, principalmente, ante el incumplimiento de deberes y obligaciones de los funcionarios policiales que generen responsabilidad administrativa. Dicha potestad se materializa a través del Decreto 900 de 1967, que establece el Reglamento de Disciplina de Carabineros de Chile 11, y por el Decreto 118 de 1982, que aprueba texto del Reglamento de Sumarios Administrativos 15 -cuyas últimas modificaciones se efectuaron por medio del Decreto 1592 de 2014. Pues bien, para el caso general de los funcionarios públicos, las bases generales y la regulación de estas materias se encuentran establecidas principalmente en la Ley 18884, Estatuto Administrativo, por lo que cualquier normación sustancial de esta materia requiere de aprobación legislativa. En cambio, para el caso de la institución policial solamente tiene rango de ley orgánica constitucional el reconocimiento de dicha potestad a sus autoridades, quedando toda la regulación de los aspectos relacionados a la dictación de decretos y reglamentos por parte del Ejecutivo, y en un encuadre competencial en que se mantiene la actuación autónoma operativa funcional a Carabineros, en relación con su autoridad política civil dependiente (Centro de Derechos Humanos, 2015: 151-152; 2017: 287-327). ${ }^{27}$

de la comisión de determinados delitos, hubo un aumento de un $249 \%$ en el delito de apremios ilegítimos cometidos por funcionarios públicos con respecto al período anterior. De esta forma, se presentaron 4.158 denuncias relacionadas con el indicado delito, junto con 1.038 corresponden a abusos contra particulares y 134 como casos de torturas. Por último, del total de víctimas, 4.17o personas denunciaron a Carabineros como los responsables de violencia institucional y, a la fecha, 294 funcionarios de la institución han sido individualizados. Para más información, véase «Estadísticas del año 2019 de la Fiscalía: Peak de denuncias registra el Ministerio Público desde inicio de la Reforma Procesal Penal», Fiscalía Nacional de Chile, 31 enero de 2020, disponible en bit.ly/3hRoHL6 y «Fiscalía eleva a 5.558 las víctimas que denuncian violaciones a Derechos Humanos desde el inicio de las manifestaciones sociales», Fiscalía Nacional de Chile, 31 de enero de 2020, disponible en bit.ly/3xPfMCy. A su vez, el Instituto Nacional de Derechos Humanos ha presentado, hasta el 19 de marzo de 2020, 1.083 querellas criminales por el delito de tortura y tratos crueles, y 91 querellas por violencia innecesaria.

27. En los Informes Anuales sobre Derechos Humanos en Chile 2015 y 2017 de la Universidad Diego 


\section{Conclusiones}

Por acción u omisión —e incluso tras las reformas constitucionales de 2005-, el poder civil no ha ejercido una dirección y un control efectivo sobre Carabineros. La policía uniformada, por su parte, supo capitalizar esta falta de conducción civil para aprovechar al máximo la arquitectura normativa cimentada en dictadura, consolidando de facto una autonomía exacerbada dentro del marco legal democrático.

Considerando que Carabineros es una institución militarizada, posee una autonomía que se explica, en parte, por su concurrencia en la Junta Militar de Gobierno de la dictadura chilena y su posterior consagración constitucional a través del Poder de Seguridad. Si bien el carácter militar de la institución tiene antecedentes - a efectos de consolidar los rasgos de obediencia, disciplina y jerarquía en Carabineros-, la integración en la Junta le extendió un tratamiento normativo especial dentro de la Administración del Estado, garantizando nichos exentos de la supervisión civil.

Las reformas constitucionales de 2005 modificaron y suprimieron los principales caracteres del Poder de Seguridad y limitaron la autonomía política institucional de dicha fuerza policial. Sin embargo, estas no alteraron las reglas de autonomía operativofuncional que se mantienen en el nivel infraconstitucional a la fecha. Además, varias de ellas protegidas por leyes de rango orgánico constitucional que cuentan con el resguardo de un mayor quórum de aprobación y del control preventivo obligatorio por parte del Tribunal Constitucional. De la revisión de dicha estructura normativa, integradas no solo por la Constitución y las leyes orgánicas constitucionales, sino que también de diversas materias contenidas en otras normas legales y administrativas - analizadas en este texto-, queda patente la persistencia de un nivel exacerbado de autonomía reconocida de manera excepcional para este organismo administrativo.

El texto demuestra que Carabineros contiene una serie de reglas excepcionales que, por su relevancia, configuran un estatuto paralelo dentro de la Administración del Estado. Si bien le son aplicables las reglas generales previstas en la Constitución y las leyes, este estatuto especial se plasma en algunas de las materias analizadas, como el régimen diferenciado en materia de carrera profesional, régimen de previsión y seguridad social, régimen presupuestario, reglas de secreto, régimen de administración de inmuebles, y régimen penal militar y disciplinario.

A su vez, el fenómeno de autonomía se grafica por la concurrencia de tres características. Primero, el reconocimiento de diversas atribuciones y competencias a las más altas autoridades policiales, las que radican principalmente en el general director. El ejercicio de estas no tiene mayor control que una mera información, de carácter global y regular en el tiempo, al Ministerio del Interior y Seguridad Pública. Segundo, la

\footnotetext{
Portales, se aborda esta discusión. En el primer caso, se formulan sendas críticas a este régimen disciplinario institucional por los problemas de deficiencia normativa, opacidad, falta de un adecuado control y determinación de las responsabilidades administrativas de las actuaciones de los efectivos policiales en barrios vulnerables, como el caso de La Legua en la ciudad de Santiago; y en el segundo caso se refiere al deficiente control interno con respecto a las denuncias por comisión de torturas por el personal policial.
} 
insuficiente capacidad de control de estas decisiones por parte del superior jerárquico respectivo de Carabineros, es decir, las autoridades políticas que dirigen la señalada Secretaría de Estado. Y tercero, la constatación de que la persistencia de estos ámbitos de autonomía se explica, en parte, como consecuencia de la equiparación normativa con las Fuerzas Armadas.

Las conclusiones de este estudio contribuyen a la comprensión de la arquitectura normativa de la institución, de cara a los procesos de reformas en desarrollo, para consolidar un control democrático de Carabineros. Las deficiencias enunciadas tienen por objeto ilustrar la autonomía de Carabineros y cómo esta afecta el cumplimiento de los mandatos constitucionales que pesan sobre la institución.

\section{Referencias}

AGÜERO, Felipe (2003). «30 años después: La ciencia política y las relaciones fuerzas armadas, Estado y sociedad». Revista de Ciencia Política (Santiago), 23 (2): 251-272. Disponible en bit.ly/3ku4Gzf.

AgüEro, Felipe y Claudio Fuentes (2009). Influencias y resistencias. Militares y poder en América Latina. Santiago: FLACSO-Chile y Catalonia.

Águila, Ernesto y Carlos Maldonado (1996). «Orden público en el Chile del siglo XX: Trayectoria de una policía militarizada». En Peter Waldmann (coordinador), Justicia en la calle: Ensayos sobre policía en América Latina. Medellín: Konrad Adenauer Stiftung, Centro Interdisciplinario de Estudios sobre el Desarrollo Latinoamericano, Institut für Spanien und Lateinamerikastudien, Universitát Aubsburg-Isla, Biblioteca Jurídica Diké.

Aguirre Bravo, Luppy (2007). «El caso Palamara Iribarne con Chile». Revista de Estudios de la Justicia, (9): 277-286. Disponible en bit.ly/3Bsrjdr.

Atria, Fernando (2013). La Constitución tramposa. Santiago: LOM.

ATria, Fernando, Constanza Salgado y Javier Wilenmann (2017). Democracia y neutralización. Santiago: LOM.

Benavides, Paula e Ingrid Jones (2012). Sistema de pensiones y otros beneficios pecuniarios de las Fuerzas Armadas y de Orden y Seguridad Pública y Gendarmería de Chile: Situación actual y proyecciones fiscales 2012-2050. Finanzas Públicas 20. Santiago: Dirección de Presupuestos, Ministerio de Hacienda de Chile. Disponible en bit.ly/3eqfbQ5.

Carabineros de Chile (2020). Glosa 18. Informe de Resultados de Gestión Operativa 2019 y Metas 2020. Disponible en bit.ly/36DxTiT.

Centro de Derechos Humanos (2015). Informe anual de derechos humanos en Chile 2015. Santiago: Universidad Diego Portales.

-. (2017). Informe anual de derechos humanos en Chile 2017. Santiago: Universidad Diego Portales.

Ciedess (2017). Sistemas de Seguridad Social Especiales en Chile: Capredena y Dipreca. Disponible en bit.ly/2UMv6RO. 
Comisión Nacional de Verdad y Reconciliación (1991). Informe de la Comisión Nacional de Verdad y Reconciliación. Disponible en bit.ly/3B 7 PDRx.

Contreras, Pablo (2011). «Independencia e imparcialidad en Sistemas de Justicia Militar: Estándares internacionales comparados». Estudios Constitucionales, 9 (2): 191248. Disponible en bit.ly/3wD4DU4.

-. (2014). Secretos de Estado. Transparencia y seguridad nacional. Santiago: Thomson Reuters.

-. (2015). «Las Fuerzas Armadas en la Constitución». En Jaime Bassa, Juan Carlos Ferrada y Christian Viera (editores), La Constitución chilena: Una revisión crítica a su práctica política. Santiago: Lom.

Contreras, Pablo y Domingo Lovera (2020). La Constitución de Chile. Valencia: Tirant lo Blanch.

Contreras, Pablo y Sebastián Salazar (2020). «Obedientes y no deliberantes: Fuerzas Armadas, autonomía y control democrático en Chile». Revista Ius et Praxis, 26 (2): 232-253. Disponible en bit.ly/3B5kRsu.

Cordero Vega, Luis (2015). Lecciones de derecho administrativo. 2. ${ }^{\mathrm{a}}$ ed. Santiago: Legal Publishing Chile.

Consejo de Seguridad Nacional de Chile (2019). ACta de sesión del ConseJo de Seguridad Nacional del 7 DE NOVIEMbre DE 2019. Disponible en Bit. $\mathrm{LY} / 3 \mathrm{HDZ} 1 \mathrm{EJ}$.

DAmmert, Lucía (2016). "Confianza en la policía en Chile. Un arma de doble filo». Dossiê: Segurança pública e reforma das polícias na América Latina, 16 (4): 575-594. Disponible en bit.ly/2UI2lWF.

-. (2019). «¿Reformar sin gobernar? Desafíos institucionales de las policías en América Latina». Ius. Revista del Instituto de Ciencias Jurídicas de Puebla, 13 (44): 89-120. DOI: $10.35487 /$ rius.v13i44.2019.444.

DíAz Tolosa, Regina Ingrid (2007). «Reforma de la Justicia Militar chilena a la luz de las consideraciones del fallo Palamara». Revista Chilena de Derecho, 34 (1): 139-151. Disponible en bit.ly/zeolRyb.

Eva PARAdA, María José (2006). «Chile ante el Sistema Interamericano: El Caso Palamara». Anuario de Derechos Humanos, 2: 157-164. Disponible en bit.ly/3zu6o7E.

Flisfisch, Ángel y Marcos Robledo (2012). Gobernabilidad democrática de la defensa en Chile. Un índice para el período 1990-2010. Santiago: PNUD.

FLOM, Hernán (2019): «Controlling bureaucracies in weak institutional contexts: The politics of police autonomy». Governance, 33 (3): 1-18. DOI: 10.1111/gove.12445.

FrüHling, Hugo (1999). «La policía en Chile: Los nuevos desafíos de una coyuntura compleja». Perspectivas, 3 (1): 63-9o. Disponible en bit.ly/3kpq2NR.

FuENTES, Claudio (2005). Contesting the iron fist: Advocacy networks and police violence in democratic Argentina and Chile. Nueva York: Routledge.

García Pino, Gonzalo, Pablo Contreras Vásquez y Victoria Martínez Placencia (2016). Diccionario constitucional chileno. Santiago: Hueders. 
Godoy, Óscar (1996). «¿Pueden las Fuerzas Armadas ser garantes de la democracia?». Estudios Públicos, 61, 269-307. Disponible en bit.ly/2URPpNz.

Heiss, Claudia y Patricio Navia (2007). «You win some, you lose some: Constitutional reforms in Chile's transition to democracy». Latin American Politics and Society, 3: 163-19o. Disponible en bit.ly/3Z8E9vr.

-. (2020). ¿Por qué necesitamos una nueva Constitución? Santiago: Aguilar.

Instituto Nacional de Derechos Humanos (2019). Informe anual sobre la situación de los derechos humanos en Chile en el contexto de la crisis social. Disponible en bit.ly/3wDDhgF.

-. (2020). Archivo de reportes de estadísticas en la crisis social. Disponible en: bit. ly/zeHkAmb.

Huneeus, Carlos (2015). La democracia semisoberana. Chile después de Pinochet. Santiago: Taurus.

JimÉnez, Guillermo, Pablo Marshall y Fernando Muñoz (2013). «La debilidad de las súper-mayorías». Revista de Derecho Pontificia Universidad Católica de Valparaíso, 41 (2), 359-393. Disponible en bit.ly/2TcWNCP.

Junta Militar de Gobierno de Chile (1973a). Primer comunicado de la Junta Militar. Disponible en bit.ly/3z1vWZD.

-. (1973b). Bando 5 del Golpe de Estado del 11 de septiembre de 1973. Disponible en bit. ly/3hEj2Ls.

Maldonado Prieto, Carlos (1990). «Los Carabineros de Chile: Historia de una policía militarizada». Ibero-Americana, Nordic Journal of Latin American Studies, 20 (3), 3-31. Disponible en bit.ly/3icrf8Q.

Molina Guaita, Hernán (2006). Derecho constitucional. Santiago: Lexis Nexis.

Montero Allende, Ricardo (2019). Dirección y control político de las instituciones armadas en Chile 2005-2018: Análisis crítico y propuestas para el futuro. Barcelona: Universitat Autònoma de Barcelona. Facultat de Ciències Polítiques i de Sociologi. Disponible en bit.ly/2UNVtXI.

Nogueira Alcalá, Humberto (2012). Derecho constitucional chileno. Santiago: Thomson Reuters.

Oficina del Alto Comisionado para los Derechos Humanos de Naciones UniDAS (2019). Informe sobre la Misión a Chile: 30 de octubre - 22 de noviembre de 2019. Disponible en bit.ly/3rdsAjz.

PeÑA, Marisol (2005). «El término de la inamovilidad relativa de los comandantes en jefe de las Fuerzas Armadas y del general director de Carabineros». En Francisco Zúñiga (coordinador), Reforma Constitucional. Santiago: Lexis Nexis.

Pion-Berlin, David y Rafael Martínez (2017). Soldiers, politicians and civilians: Reforming civic-military relations in democratic Latin American. Cambridge: Cambridge University Press.

Ponce Solé, Juli (2019). La lucha por el buen gobierno y el derecho a una buena administración mediante el estándar jurídico de diligencia debida: Cuadernos de la Cátedra de Democracia y Derechos Humanos 15. Madrid: Universidad de Alcalá. 
Silva Bascuñán, Alejandro y María Pía Silva Gallinato (2002). «Cambios en el régimen de las Fuerzas Armadas». Revista Ius et Praxis, 8 (1): 71-94. Disponible en https://bit.ly/2TvGvFt.

Vallejos Muñoz, Camilo (2019). «Carabineros de Chile y la seguridad nacional: Una mirada a las representaciones policiales del orden público durante la dictadura, 1973-1990». Revista Historia y Justicia, 13: 1-25. Disponible en bit.ly/3rldUza.

Verdugo Marinkovic, Mario (2005). «Notas a la reforma constitucional en lo que atañe a las Fuerzas Armadas y Consejo de Seguridad Nacional». En Francisco Zúñiga (coordinador), Reforma Constitucional. Santiago: Lexis Nexis.

Verdugo Marinkovic, Mario, Emilio Pfeffer Urquiaga y Humberto Nogueira Alcalá (2002). Derecho constitucional. Santiago: Jurídica de Chile.

Weibel, Mauricio (2018). Ni orden ni patria. La trama secreta del Pacogate. Santiago: Aguilar.

\section{Sobre los autores}

Pablo Contreras Vásquez es doctor en Derecho y master in Laws (LL.M.) de la Universidad de Northwestern, Evanston, Illinois, Estados Unidos; magíster en Gobierno y Sociedad y Abogado, licenciado en Ciencias Jurídicas y Sociales de la Universidad Alberto Hurtado. Actualmente, es profesor asociado de la Facultad de Derecho de la Universidad Autónoma de Chile. Su correo electrónico es pablo.contreras@uautonoma.cl. (D) https://orcid.org/oooo-0002-1131-182X.

Ricardo Montero Allende es máster en Defensa y Seguridad Interamericana, Inter American Defense College, Washington D.C.; máster en Relaciones Internacionales, Seguridad y Desarrollo, Universidad Autónoma de Barcelona; abogado, licenciado en Ciencias Jurídicas y Sociales de la Pontificia Universidad Católica de Chile. Actualmente, es convencional constituyente por el Distrito 18 (Maule Sur) para la Convención Constitucional de Chile. Su correo electrónico es rimonter@uc.cl. (iD) https://orcid. org/0000-0003-0817-0912.

Sebastián Salazar Pizarro es doctorando en Derecho y Ciencia Política de la Universitat de Barcelona; máster Universitario en Derecho Público, Universidad Carlos III de Madrid; y abogado, licenciado en Ciencias Jurídicas y Sociales de la Universidad Alberto Hurtado. Actualmente, es docente adjunto de la Escuela de Ciencias Sociales de la Universidad de O’Higgins. Su correo electrónico es sebastian.salazar@uoh.cl. (D) https://orcid.org/0000-0002-4326-3017. 
La Revista de Derecho Público es publicada desde 1963 por el Departamento de Derecho Público de la Facultad de Derecho de la Universidad de Chile. Aparece dos veces al año. Su propósito es la difusión de los avances del derecho público nacional e internacional y la socialización de artículos de investigación inéditos de la comunidad académica nacional e internacional.

DIRECTORA

Ana María García Barzelatto

SECRETARIO DE REDACCIÓN

Felipe Peroti Díaz

fperoti@derecho.uchile.cl

SITIO WEB

revistaderechopublico.uchile.cl

CORREO ELECTRÓNICO

publico@derecho.uchile.cl

LICENCIA DE ESTE ARTÍCULO

Creative Commons Atribución Compartir Igual 4.o Internacional

La edición de textos, el diseño editorial

y la conversión a formatos electrónicos de este artículo

estuvieron a cargo de Tipográfica

www.tipografica.io 